\title{
Plasma Homocysteine and Methylenetetrahydrofolate Reductase Gene Polymorphism in Human Health and Disease: An Update
}

\author{
Govindaiah Vinukonda
}

Department of Pathology, New York Medical College, Valhalla, New York, USA

KEYWORDS Methylene tetrahydrofolate (MTHFR); homocysteine; coronary artery disease (CAD); coronary heart disease (CHD); myocardial infractions (MI); genetic polymorphism; genotype

\begin{abstract}
The strongly rising prevalence of chronic diseases in most of the developing \& developed countries causes major problems in the health systems. High blood cholesterol caused by high fat consumption, hypertension, low physical activity and smoking are the most discussed factors responsible for the high rate of myocardial infraction, stroke, peripheral arterial disease in these countries. This review is to evaluate epidemic relationship between plasma homocysteine and MTHFR gene polymorphism in cardiovascular disease and is based on published data from different parts of world and from Indian sub-continent. Circulating total homocysteine is independent risk factor for various cardiovascular conditions irrespective of ethnicity. Many studies well documented by large scale case-controls. The difference between cases and controls is about $2-5 \mu \mathrm{mol} / \mathrm{L}$ and to quantify small differences, HPLC with fluorescence detection is the best method to assess small differences between cases and controls. MTHFR 677 CT mutation is not associated with CAD, CVD, CHD and MI patients except in few studies reported from Japanese and Netherlander populations. The data from Indian sub-continent is inadequate to assess these associations.
\end{abstract}

\section{INTRODUCTION}

The strongly rising prevalence of chronic disease in most of the developed and developing countries causes major problems in the health systems. High blood cholesterol caused by high fat consumption, hypertension, low physical activity and smoking are the most discussed factors responsible for the high rate of myocardial infraction, stroke, peripheral arterial disease in these countries.

In 1969, Mc Cully made the clinical observation linking elevated homocysteine concentrations with vascular disease. He reported autopsy evidence of extensive arterial thrombosis and atherosclerosis in two children with elevated plasma homocysteine concentrations and homocysteinuria. On the basis of this observation, he proposed that elevated plasma homocysteine can cause atherosclerotic vascular disease. The term "homocyst(e)ine" is used to define the combined pool of homocysteine, homocysteine mixed disulfides involving homocysteine and homocysteine thio-lactone found in the plasma of patients with hyperhomocysteinemia.

Since 1992, mild elevation in the total

Address for Correspondence: Dr. Govindaiah Vinukonda Department of Pathology, New York medical College Valhalla, NY: 10595, USA

Telephone: $914-594-3103$

E-mail: g_vinukonda@nymc.edu homocysteine (tHCY) concentrations have been described as risk factors for arteriosclerosis, venous thrombosis as well as for obstetric complications. Since the mid-eighties, many studies have documented that a moderately elevated plasma homocysteine level is also strong and independent risk factor for atherosclerotic diseases, such as myocardial infraction, stroke or peripheral vascular disease

The main objective of the present review was to evaluate epidemic relationship between plasma homocysteine and MTHFR gene polymorphism in cardiovascular disease. The review was based on published data from different parts of world.

\section{METABOLIC BACKGROUND}

Homocysteine is a non-protein forming, sulfhydryl-containing amino acid which results from methionine metabolism. Homocysteine is at the intersection of two metabolic pathways, the transsulfuration pathway and the remethylation cycle. Homocysteine is either transsulfurated to cystathionine or remethylated to methionine depending on methionine supplied by diet. In remethylation, HCY acquires a methyl group from 5-methylenetetrahydrofolate (5-MTHF) to form methionine. The reaction occurs in all tissues, is catalyzed by MS and is vitamin B-12 dependent. Alternatively the methyl group is provided by betaine. However, this reaction is confined mainly to the lever and is of less importance. Methionine 
is transformed to S-adenosyl-methionine (SAM), which serves primarily as a universal methyl donor. In this reaction, S-adenosyl-homocysteine (SAH) is formed and subsequently hydrolyzed to homocysteine. SAH is a potent competitor to SAM as different binding sites and there by can inhibate the methylation. In transsulfuration path way HCY condenses with serine to cystathionine (CYS). This reaction, canalized by Cystathionine beta synthase (CBS), is vitamin B-6 dependent. In secondary option, catalysed by cystathionase, CYS is hydrolyzed to cysteine and alfa keto butyrate. A homocysteine accumulation can be caused either by transsulfuration defects based on Cystathionine beta synthase deficiency or by remethylation defects based on MS deficiency or 5, 10-methylenetetrahydrofolate reductase (MTHFR) deficiency. Additionally, a moderately elevated homocysteine level can also be caused by a shortage of the co-factors vitamin B-6, vitamin B-12, or folic acid (Wolfgang et al. 2001)

SAM plays an important role in co-ordinating the regulation of remethylation and transsulfuration. SAM activates the CBS and inhibits the MTHFR reaction which forms 5-MTHF. The utilization of SAM is regulated by glycine-Nmethyl transferase (GNMT), which transfers the methyl group of SAM to glycene to form $\mathrm{N}$ methyle glycene (sacrosine). This reaction strongly inhibited by 5 MTHF polyglutamates. Genetic and acquired abnormalities in the function of these enzymes or deficiencies in folate or vit B6 or B 12 cofactors can therefore lead to elevated concentrations of intracellular homocysteine, which is then released to the plasma.

\section{Measurement of Plasma Homocysteine}

The majority of the clinical studies involving homocysteine have relied on the measurement of total homocysteine, which includes homocysteine, mixed disulfides involving homocysteine, homocysteine thiolactone, free homocysteine and protein bound homocysteine. Protein bound (i.e. disulfide linked) homocysteine accounts 70-80 percent of total pool. So far, free homocysteine in plasma has been determined by ion-exchange chromatography using an amino acid analyzer or by HPLC with electro-chemical detection. However these methods have some disadvantages with respect to sensitivity and selectivity. Further these methods neglect the existence of protein bound homocysteine in the plasma.
Recently, a new fluorogenic thiol-specific reagent, ammonium 7-fluorobenzo 2 oxa-1,3 diazole -4 sulfonate ( SBD-F) has been developed for the measurement of biologically important thiols. With this method the derived products are fluorescent and stable for long time and able to detect nanomole concentrations (Araki and Sako 1987)

In another review on methodological assessment, the study compared commercially available methods with in house HPLC SBD-F base analysis and concluded that in house HPLC is able to detect minor variability in case controls than other methods (Harry et al. 2000). The rationale discussing these methods for any case control study required exact measurement because most of the disease cases the difference between case -controls is around 3-5 micromole.

\section{Association between Plasma Homocysteine and Cardiovascular Disease}

Starting from 1990's to present the major studies appeared on homocysteine and cardiovascular disease, relating to different clinical conditions, are presented in Table 1 . The main clinical conditions include coronary artery disease (CAD), cerebrovascular disease (CVD), peripheral vascular disease (PVD), myocardial infraction (MI) and coronary heart disease (CHD). Most of these are well defined case-control and nested-case control studies. The main emphasis here is to look at the association of elevated HCY and cardiovascular disease and distribution of mean HCY levels in case controls.

There are 20-25 important studies which were validated for the association of HCY and vascular diseases. It is interesting to discuss in detail a few studies shown in the Table 1. In 1991 Taylor et al. carried out a case control study of 214 patients with clinical symptoms for arterial occlusive disease, stroke, cerebral transient ischemic attacks and cerebral vascular disease. The study concluded that elevated HCY is associated with progression of lower extremity; coronary artery disease and cerebrovascular disease. In this study they have used in house HPLC method to estimate homocysteine. The reported levels of $\mathrm{HCY}$ in cases and controls were 14.37 and $10.10 \mu \mathrm{mol} / \mathrm{L}$ respectively.

In 1992, Stampfer et al. carried out a prospective US physicians' health study by recruiting 14916 male physicians with no history of MI or stroke, were followed up to 5 years. Initially all 
Table 1: Distribution of Homcysteine in different cardiovascular conditions

\begin{tabular}{llclll}
\hline & \multicolumn{2}{c}{ Mean HCY \pm S.D $(\mu \mathrm{mol} / \mathrm{L})$} & & \\
\cline { 2 - 3 } Disease & Cases & Controls & & Reference & Significance \\
\hline 1.CAD,CVD,PVD & $14.37 \pm 6.89$ & $10.10 \pm 2.16$ & & Taylor et al. 1991 & significant \\
2.Acute MI & $11.10 \pm 4.0$ & $10.50 \pm 2.80$ & & Stephan et al. 1992 & significant \\
3.Ischemic CVA & $11.10 \pm 4.0$ & $10.60 \pm 3.40$ & & Verhoef et al. 1994 & NS \\
4.CHD & $12.70 \pm 4.7$ & $11.3 \pm 3.70$ & & Arnesenet al. 1995 & significant \\
5.CVA & 13.7 & 11.9 & Perry et al. 1995 & significant \\
6.CAD,CVD,PVD & 11.25 & 9.73 & Graham et al. 1997 & significant \\
7.CAD & 11.4 & NA & Nygord et al. 1997 & significant \\
8. MI & $13.1 \pm 5.0$ & NA & Bonna et al. 2006 & significant \\
9.CHD & $12.15 \pm 5.2$ & $10.1 \pm 4.21$ & Stehouwer 1998 & NA \\
10.PAD & $13.0 \pm 4.0$ & $10.25 \pm 3.9$ & Boushey 1995 & NA \\
11.CVD & $14.1 \pm 5.1$ & $12.5 \pm 4.0$ & Kluijtmas et al. 96 & NA \\
12.CAD & 12.7 & 11.6 & Verhoef et al. 1997 & significant \\
13.CAD & 10.3 & 8.9 & Yoo JN et al. 1999 & NA \\
14 CVD & $11.1 \pm 4.3$ & $12.5 \pm 6.0$ & Zee et al. 2007 & NA \\
15. CHD & 12.5 & 9.45 & Refsum et al. 2007 & NS \\
16. CHD & $12.6+4.6$ & $12.4+3.4$ & Deepa et al. 2001 &
\end{tabular}

these physicians were recorded baseline homocysteine. After 5 years follow up 271 were developed myocardial infractions and their blood was analyzed for homocysteine with appropriate controls. The high levels of homocysteine were associated with MI and it is an independent risk for MI than for other coronary diseases. These findings were supported by Arnesen et al. 1995 in a prospective Tromso study. Similar results were reported by Alfthan et al. (1994). In a recent study Bonaa et al. (2006) reported a harmful effect from combined vitamin-B treatment for lowering the elevated homocysteine in 3749 acute myocardial infraction patients.

In 1994 Verhoef et al. carried out a doubleblind placebo control study of 22,071 US male physicians with no history of stroke, ischemic attack, and MI. After 5 year follow-up 109 developed ischemic stroke. This study concluded that elevated homocysteine is not an independent risk factor for stroke.

In 1997, Graham et al. measured plasma homocysteine in 750 cases with clinical conditions for atherosclerotic vascular disease cardiac, cerebral, peripheral disease and 800 control samples of both the sexes and concluded that elevated homocysteine is an independent risk factor as other factors like smoking and hyperlipidimia. In another but prospective study involving 587 angiographically proven CAD patients Nygard et al. (1997) reported association with elevated homocysteine. Interestingly, Homocysteine level, more than $15 \mu \mathrm{mol} / \mathrm{L}$, is a strong predictor of mortality in these groups of patients.
In a British Regional cohort study Perry et al. (1995) randomly selected patients -from general practice centers of 18 towns and were followed up with initially normal homocysteine levels. Patients who developed stroke after follow up were checked for HCY and concluded that elevated HCY in this group of patients is a strong independent risk factor for stroke. Refsum et al. 2006 in a recent "Hordaland Homocysteine study", a community based 5 years follow-up study of homocysteine and its determinant factors, showed that increased HCY is associated with multiple clinical conditions including cardiovascular mortality.

In a Korean population based coronary artery disease patient study, Yoo et al. (1999) reported that elevated homocysteine was not only an independent risk factor for the occurrence of CAD but also a significant predictor of triple vessel disease in CAD patients.

Zee et al. (2007) reported a US based study of comprehensive and simultaneous assessment of risk factors- dietary intake, plasma homocysteine, and MTHFR genotype status- in relation to the incidence CVD in the same study population. This study, which is the largest to date that has examined these simultaneously measured risk factors, concluded that the baseline plasma homocysteine was associated with the incidence of CVD, but this association was weakened and became non-significant after adjustment for cardiovascular risk factors and socioeconomic status.

Stehouwer et al. (1998) carried out a follow 
up study of Zutphen elderly men for 10 years and reported that high levels of homocysteine were associated with an increased risk of dying from coronary heart disease but not with an increased risk of MI.

\section{Association of 677 C-T MTHFR Gene Polymorphism and Cardiovascular Diseases}

The enzyme 5, 10-methylenetetrahydrofolate reductase (MTHFR) catalyzes the conversion of 5, 10 methylenetetrahydrofolate to 5-methyltetrahydrofolate and this enzyme represents a major enzyme in the folate-dependent regulation of methionine and homocysteine concentration in the circulation. The human gene has been mapped to chromosomal region $1 \mathrm{p} 36.3$. A human genomic clone $(17 \mathrm{~kb})$ was found to contain the entire cDNA sequence of $2.2 \mathrm{~kb}$; there were 11 exons ranging in size from $102 \mathrm{bp}$ to $432 \mathrm{bp}$. Intron sizes ranged from $250 \mathrm{bp}$ to $1.5 \mathrm{~kb}$ with one exception of $4.2 \mathrm{~kb}$.
Currently, a total of 41 rare but deleterious mutations and about 60 polymorphisms have been reported. More than fifteen mutations have been identified in relation to the enzyme activity of the MTHFR gene: 14 rare mutations associated with severe enzymatic deficiency and the common 677 C-T polymorphism (ds SNP ID: rs1801133) associated with a milder deficiency. The 677 C-T common polymorphism converts alanine to a valine at position 222 and its reduced specific activity and increased thermolability caused by mildly elevated homocysteine has been implicated in complex and multifactorial diseases: occlusive vascular disease, neural tube defects, and colon cancer etc. In the present review we summarize the state of relevant findings of this common mutation in cardiovascular disease from different parts of the world.

Several studies have evaluated the association between mutant genotypes (CT/TT) and the presence of cardiovascular disease. The important and similar data available from studies

Table 2: Distribution of MTHFR $677 \mathrm{C}$ to $\mathrm{T}$ mutation in cases and controls among different populations of the world.

\begin{tabular}{|c|c|c|c|c|c|c|c|c|c|c|c|}
\hline \multirow[t]{2}{*}{ Disease } & \multirow[t]{2}{*}{$N$} & \multicolumn{3}{|c|}{ Cases } & \multirow{2}{*}{$\begin{array}{r}t- \\
\text { allele }\end{array}$} & \multirow[t]{2}{*}{$N$} & \multicolumn{3}{|c|}{ Controls } & \multirow{2}{*}{ allele } & \multirow[t]{2}{*}{ Author \& Ref. } \\
\hline & & $C C$ & $C T$ & $T T$ & & & $C C$ & $C T$ & $T T$ & & \\
\hline \multicolumn{12}{|c|}{ Studies with No Association } \\
\hline \multirow{2}{*}{$\begin{array}{l}\text { CAD } \\
\text { CAD }\end{array}$} & 510 & 241 & 212 & 57 & 0.32 & 168 & 73 & 73 & 22 & 0.34 & Anderson et al. 1997-USA \\
\hline & 382 & 173 & 172 & 37 & 0.33 & 122 & 53 & 52 & 17 & 0.35 & Emmanouil et al. 2003-USA \\
\hline CAD & 981 & 458 & 442 & 81 & 0.31 & 981 & 443 & 442 & 96 & 0.32 & Meisel et al. 2001-Germany \\
\hline CAD & 1893 & 891 & 805 & 197 & 0.32 & 560 & 242 & 254 & 64 & 0.34 & Gardemann et al. 1999-Germany \\
\hline CAD & 180 & 91 & 66 & 23 & $\begin{array}{r}0.31 \\
\mathbf{0 . 3 1 3}\end{array}$ & 104 & 49 & 46 & 9 & $\begin{array}{l}0.3 \\
\mathbf{0 . 3 2}\end{array}$ & Reinhardt et al. 1998-Germany \\
\hline CAD & 85 & 30 & 40 & 15 & 0.41 & 152 & 56 & 68 & 28 & 0.41 & kim et al. 2001-Korea \\
\hline CAD & 140 & 40 & 74 & 26 & $\begin{array}{l}0.45 \\
\mathbf{0 . 4 3}\end{array}$ & 140 & 37 & 78 & 25 & $\begin{array}{l}0.46 \\
\mathbf{0 . 4 3 5}\end{array}$ & Hong et al. 2001-Korea \\
\hline CAD & 131 & 59 & 59 & 13 & 0.32 & 100 & 45 & 48 & 7 & 0.31 & Verhoef et al. 1994 \\
\hline CAD & 278 & 90 & 148 & 40 & 0.41 & 137 & 42 & 70 & 25 & 0.44 & Girelli et al. 1998-Italy \\
\hline CAD & 151 & 69 & 71 & 11 & $\begin{array}{l}0.31 \\
\mathbf{0 . 3 5}\end{array}$ & 91 & 47 & 39 & 5 & $\begin{array}{l}0.27 \\
\mathbf{0 . 3 4}\end{array}$ & Sazcia et al. 2006-Turkey \\
\hline MI & 1152 & 527 & 515 & 110 & 0.32 & 1165 & 606 & 544 & 15 & 0.25 & Gardemann et al. 1999-Germany \\
\hline MI & 200 & 90 & 87 & 23 & 0.33 & 554 & 257 & 238 & 59 & 0.32 & Anderson et al. 1997-USA \\
\hline MI & 532 & 229 & 250 & 53 & 0.33 & 311 & 134 & 137 & 40 & 0.35 & Adams et al.1996-UK \\
\hline MI & 181 & 78 & 81 & 22 & 0.35 & 601 & 280 & 262 & 59 & 0.32 & Tanis et al. 2004 \\
\hline Stroke & 27 & 20 & 7 & 0 & 0.13 & 101 & 75 & 25 & 1 & 0.13 & Sirachainan et al. 2006-Thailand \\
\hline Stroke & 120 & 52 & 52 & 16 & 0.35 & 259 & 115 & 119 & 25 & 0.33 & Sazcia et al. 2006-Turkey \\
\hline \multicolumn{12}{|c|}{ Studies with Association } \\
\hline \multirow{2}{*}{$\begin{array}{l}\text { CAD } \\
\text { CVD }\end{array}$} & 735 & 337 & 328 & 70 & 0.32 & 1250 & 617 & 527 & 106 & 0.29 & Kluijtmans et al. 1997-Nethrlands \\
\hline & 60 & 30 & 21 & 9 & $\begin{array}{l}0.32 \\
\mathbf{0 . 3 2}\end{array}$ & 111 & 63 & 42 & 6 & $\begin{array}{l}0.24 \\
0.265\end{array}$ & Klujtmans et al. 1996-Nethreland \\
\hline CHD & 214 & 69 & 84 & 61 & 0.47 & 310 & 110 & 158 & 42 & 0.39 & Ou et al. 1998-Japan \\
\hline CAD & 362 & 116 & 188 & 58 & $\begin{array}{l}0.42 \\
\mathbf{0 . 4 1}\end{array}$ & 771 & 335 & 358 & 78 & $\begin{array}{l}0.33 \\
\mathbf{0 . 3 2}\end{array}$ & Morita et al. 1997-Japan \\
\hline MI & 250 & 90 & 110 & 50 & 0.42 & 201 & 74 & 102 & 25 & 0.38 & Izumi et al. 1996-Japan \\
\hline MI & 111 & 44 & 48 & 19 & 0.39 & 105 & 53 & 45 & 7 & 0.28 & Gallagher et al. 1996-Ireland \\
\hline
\end{tabular}




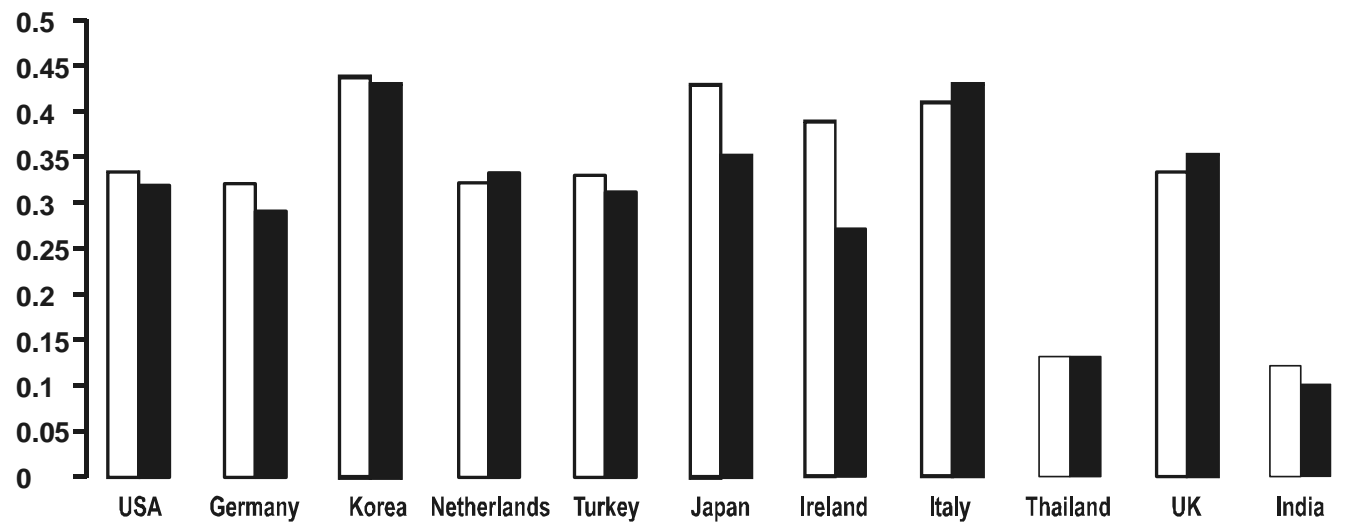

Fig. 1. Distrubution of MTHFR mutatnt allete among world poplations in Cardiovascular disease and controls

conducted at different geographical regions are shown in the Table 2. The two papers appeared from USA with angiographically proven CAD patients (Emmanouil 2003; Anderson et al. 1997) did not present statistically significant results between cases and controls. The pooled mutant $\mathrm{t}$-allele frequency was 0.325 and 0.345 in cases and controls, respectively. The three important well characterized angiographically proven CAD case -control studies appeared from Germany (Meisel 2001; Gardemann 1999; Reinhardt 1998) also did not yield statistically significant results. The mutant allele frequency for the pooled data from this region is 0.31 and 0.32 for cases and controls, respectively. Two more reports on Korean population by Kim (2001) and Hong (2001) presented similarly non-significant differences in mutant allele frequency between cases and controls (0.43 against 0.44$)$. There were two studies from Netherlands on CAD and MI patients and the results from these studies were also not significant.

Interestingly, the studies reported on Japanese population: Ou (1998) on CHD, Morita (1997) on CAD and Izumi (1996) on MI showed significant differences between cases and controls. Similarly, two other studies from Netherland (Kluijtmas 1996, 1997) on CAD and CVD and one more from Ireland (Gallagher1996) on MI reported significant differences.

\section{Studies from the Indian Sub-continent}

There are a few studies available from the Indian sub-continent on homocysteinemia and MTHFR polymorphism although these data (Table 3) were not uniform. Nevertheless, Kalita et al. (2006) reported $677 \mathrm{C}$ to T MTHFR

Table 3: Distribution of Homcysteine and MTHFR gene mutation among Indian population.

\begin{tabular}{|c|c|c|c|c|c|c|c|c|}
\hline \multirow[b]{2}{*}{ Disease } & \multicolumn{5}{|c|}{ Mean HCY ( $\mathrm{Hmol} / \mathrm{L})$} & & \multirow[t]{2}{*}{ Reference } & \multirow[t]{2}{*}{ Significance } \\
\hline & \multicolumn{2}{|c|}{ Cases (N) } & & \multicolumn{2}{|c|}{ Controls $(N)$} & & & \\
\hline CHD & \multicolumn{2}{|l|}{9.41} & & \multicolumn{2}{|c|}{10.98} & & Chacko et al. 1998 & NS \\
\hline CVD & \multicolumn{2}{|l|}{19.7} & & \multicolumn{2}{|c|}{20.1} & & Refsum 2001 & NS \\
\hline CVD & \multicolumn{2}{|l|}{16.5} & & \multicolumn{2}{|c|}{11} & & Naushad 2007 & Significant \\
\hline CAD & \multicolumn{2}{|l|}{15} & & \multicolumn{2}{|c|}{9.61} & & Patel et al. 2006 & $\mathrm{NS}$ \\
\hline Slum VS Healthy & \multicolumn{2}{|l|}{23.2} & & \multicolumn{2}{|c|}{25.2} & & Misra et al. 2002 & NS \\
\hline Healthy women & \multicolumn{2}{|l|}{ NA } & & \multicolumn{2}{|c|}{9} & & Pandey et al. 2006 & NS \\
\hline Vegetarians VS & \multirow{2}{*}{\multicolumn{2}{|c|}{14.6}} & & \multirow{2}{*}{\multicolumn{2}{|c|}{13.3}} & & Kumar et al. 2005 & NS \\
\hline Non-Vegetarians & & & & & & & & \\
\hline \multicolumn{9}{|c|}{ MTHFR 677 C-Mutation: } \\
\hline & $C C$ & $C T$ & $T T$ & $C C$ & $C T$ & $T T$ & & \\
\hline Stroke & 39 & 16 & 3 & NA & NA & NA & Kalita et al. 2006 & Significant \\
\hline CVD & 133 & 29 & 1 & 142 & 21 & 1 & Naushad et al. 2007 & Significant \\
\hline General Population & & NA & & 147 & 49 & 6 & Kumar et al. 2005 & NA \\
\hline
\end{tabular}


genotypes among 58 stroke patients with a genotypic distribution of TT: 3, CT: 16 and CC: 39 wild type with the mean homocysteine concentration of $13.9 \mu \mathrm{mol} / \mathrm{L}$. They have shown significant association. Chako et al. (1998) carried out a case-control study consists of 56 coronary heart disease patients and 53 controls and reported the HPLC based estimation of mean HCY as 10.98 in cases and $9.41 \mu \mathrm{mol} / \mathrm{L}$ in controls, respectively, which is not significantly different between cases and controls. In another study Pandey et al. (2006) reported similar results with no significant difference in the mean HCY of cardiovascular disease patients and controls.

In 2001 Refsum et al. conducted a study at pune population consisting of CVD patients with diabetes and without diabetes along with the healthy controls. The mean homocysteine among healthy controls is $19 \mu \mathrm{mol} / \mathrm{L}$, and in CVD patients is $20 \mu \mathrm{mol} / 1$ and in another group CVD with diabetes is about $20.2 \mu \mathrm{mol} / \mathrm{L}$. The data showed no significant association between the groups.

Patel et al. (2006) conducted a well designed case-control study to estimate excess risk of cardiovascular disease among the immigrant Gujaratis in UK verses the Gujaratis living in India. The reported mean HCY in the immigrant Men and women in UK was 10.4 and $8.7 \mu \mathrm{mol} / \mathrm{L}$, respectively, against 16.9 and $12.9 \mu \mathrm{mo} / \mathrm{L}$ found for their counterparts in India. In another study, Kumar et al. (2005) reported the distribution of HCY in vegetarian and non-vegetarian populations along with MTHFR genotypes. The mean HCY in Vegetarian and non-vegetarian population was 14.6 and $13.3 \mu \mathrm{mol} / \mathrm{L}$, respectively. The MTHFR genotypes were reported to be the following: wild type CC 147 and mutant heterozygote CT: 49 and mutant homozygote TT: 6. Misra (2002) reported HCY levels in a group living in urban slum area (Group-1) and in another group of healthy individuals living in the surroundings as controls (Group-2). The serum HCY was measured using ELISA kit and the mean HCY was reported to be 23.2 micromoles/ L in cases and 20.8 in controls, the mean difference being statistically non-significant.

\section{DISCUSSION}

\section{Circulating Homocysteine and Cardiovascular Disease}

Interest in the prognostic value of the association between circulating HCY and disease continues to grow. There is already a large body of evidence indicating that the elevated plasma HCY was related to risk of coronary, cerebral and peripheral arterial disease. Based on their research findings, Vollset et al. (2000) reported that hyperhomocysteinemia might also be an important biological marker for, and possibly even a cause of or contributor to, complications and adverse outcome of pregnancy and cancer.

The established normal range of fasting tHCY in healthy adults is usually $5-15 \mathrm{~m} \mathrm{~mol} / \mathrm{L}$ (Male: 15 $\mathrm{m} \mathrm{mol} / \mathrm{L}$; Female: $8 \mathrm{~m} \mathrm{~mol} / \mathrm{L}$ ) with a mean of about $10 \mathrm{mmol} / \mathrm{L}$. Hyperhomocysteinemia is defined as a plasma tHCY $>15 \mathrm{~m} \mathrm{~mol} / \mathrm{L}$ and is denoted as a moderate (15-30 $\mathrm{m} \mathrm{mol} / \mathrm{L})$, intermediate $(30-100 \mathrm{~m}$ $\mathrm{mol} / \mathrm{L})$ and severe (>100 m mol/L) hyperhomocysteinemia (George et al. 1998; Kang et al. 1992). The normal range of homocysteine is population specific and is required to establish normal range for a population in order to under stand the disease pathology of the cases. Further, the distribution of HCY in males and females is significantly different.

It is evident from Table 1 that the multiple prospective and case-control studies have shown that a mild elevated level of circulating homocysteine is an independent risk factor for vascular disease. Most of the studies with multiple cardiovascular conditions consistently show higher level of homocysteine in cases than in controls suggesting that homocysteine promotes cardiovascular disease conditions through variety of mechanisms. An overall assessment of the epidemiology association studies indicates that 2-5 m mol/L-increased levels of homocysteine are capable of developing cardiovascular problems.

\section{MTHFR 677 C-T Polymorphism and Cardiovascular Disease}

Several studies have evaluated the association between mutant genotype and cardiovascular problem and most of these studies yielded negative results as shown in Table 2 . There were two studies from Netherlands reported by Kluijtmans et al. $(1996,1997)$ who performed a meta-analysis combining data from eight studies, revealing an increased risk for CAD of borderline significance. However, the definition of the CAD was as a history of MI rather than $\mathrm{CAD}$ on angiography. 
The allele frequency of this mutation is comparablein all the studied populations with little differences except for the Korean Population. The distribution was in Hardy-Weinberg equilibrium. These results suggest that this mutation is highly prevalent across the ethnic groups and can be regarded as a balanced polymorphism that escaped from natural selection through the long history of humanity. Such a polymorphism does not usually cause a serious lethal disorder as a single factor.

The pooled t-allele frequency of various cardiovascular conditions for each country and for cases and controls were graphically presented in the Figure 1. Pooled data of different studies of various cardiovascular conditions for each country suggest that the highest incidence of mutant allele was recorded for Korean populations followed by the Japanese. The lowest mutant allele frequency is reported among Thailand population followed by the Indian populations. To address the problem of lowest frequency among Indian and Thai populations at this point there are no well designed casecontrol or nested-control studies with power calculation for sample size.

\section{Perspectives and Future Directions Pertaining to the Indian Populations}

The populations of the Indian subcontinent is more than a billion comprising of 4693 communities with several thousands of well defined endogamous groups, 325 functional languages and 25 scripts. The data from the Indian sub continent is too inadequate; there is no well designed case-control or population based study. For example, the normal ranges of homocysteine are to some- extent dependent on nutritional status. The diet consumption in different region is unique and interesting for studying homocysteine associated diseases. It is also important to study the population specific incidence of MTHFR $677 \mathrm{C}$-T polymorphisms since it has the reduced enzyme activity.

\section{CONCLUSION}

Circulating total homocysteine is independent risk factor for various cardiovascular conditions irrespective of ethnicity. The difference between cases and controls is about $2-5 \mu \mathrm{mol} / \mathrm{L}$ and to quantify small differences, HPLC with fluore- scence detection is the best method to assess small differences between cases and controls. MTHFR 677 C-T mutation is not associated with cardiovascular disease except in two studies reported from the Japanese and Netherlandish populations.

\section{REFERENCES}

Adams M, Smith PD, Martin D, Thompson JR, Lodwick D, Samani NJ 1996. Genetic analysis of thermolabile methylenetetrahydrofolate reductase as a risk for myocardial infraction. $Q J$ Med, 89(6): 437-444.

Alfthan G, Pekkanen J, Jauhiainen M et al. 1994. Relation of serum homocysteine and lipoprotein (a) concentrations to atherosclerotic disease in a prospective Finnish population based study. Atherosclerosis, 106: 9-19

Anderson JL, King G.J, Thomson MJ et al. 1997. A mutation in the Methylenetetrahydrofolate reductase gene is not associated with increased risk for coronary artery disease or myocardial infarction. J Am Coll Cardiol, 30(5): 1206-1211.

Araki Atsushi, Sako Yoshiyasu 1987. Determination of free and total homocysteine inhuman plasma by high-performance liquid chromatography with fluorescence detection. Journal of Chromatography, 422: 43-52.

Arnensen E, Refsum H, Bonna KH, Ueland PM, Forde $\mathrm{OH}$, Nordrehaug JE 1995. Serum total homocysteine and coronary heart disease. Int J Edemiol, 24: $1924-1930$.

Bonaa KH, Njolstad I, Ueland PM, Schirmer H et al. 2006. Homocysteine lowering and cardiovascular events after acute myocardial infraction. $N$ Eng $J$ Med, 354: 1578-1588.

Chacko KA 1998. Plasma Homocysteine levels in patients with coronary heart disease. Indian Heart Journal, 50(3): 295-299.

Emmanouil S Brilakis, Peter B Berger, Karla V Ballman, Rima Rozen 2003. Methylenetetrahydrofolate reductase (MTHFR) $677 \mathrm{C}>\mathrm{T}$ and methionine synthase reductase (MTRR) 66A $>\mathrm{G}$ polymorphism: association with serum homocysteine and angiographic coronary artery disease in the era of flour products fortified with folic acid. Atherosclerosis, 168: 315-322.

Gallagher PM, Meleady R, Shields DC et al.1996. Homocysteine and risk of premature coronary heart disease. Evidence for a common gene mutation. Circulation, 94(9): 2154-2158

Gardemann A, Weidemann H, Philipp M et al. 1999. The TT genotype of the methylenetetrahydrofo late reductase C677T gene polymorphism is associated with the extent of coronary atherosclerosis in patients at high risk for coronary artery disease. Eur Heart J, 20(8): 584-592.

George N Welch, Joseph loscalzo 1998. Homocysteine and Atherothromobosis. The New Eng Journal of Medicine, 338(15): 1042-1050.

Girelli BD, Friso S, Trabetti E, Oliveri O, et al 1998. Methylenetetrahydrofolate reductase C677T mutation, plasma homocysteine, and Folate in subjects 
from Northern Italy with or without angiographically documented severe coronary atherosclerotic Disease: Evidence for an important genetic-environmental interaction. Blood, 91(11): 4158-4163.

Graham IM, Daly LE, Refsum H et al. 1997. Plasma homocysteine as a risk factor for vascular disease: the European concerted action project. JAMA, 277: $1775-1771$.

Harry H Yu, Rana Joubran, Muhammad Asmi, Terence Law, Nader Rifai 2000. Agreement among four homocysteine assays and results in-patients with coronary atherosclerosis and controls. Clinical Chemistry, 46(2): 258-264

Hong SH, Song J, Kim JQ 2001, Genetic variation of the methylenetetrahydrofolate reductase and cystathionine beta-synthase genes in Korean patients with coronary artery disease and a new polymorphism in intron 7. Mol Cell Probes, 15(2): 119-123

Izumi M, Iwai N, Ohmichi N, Nakamura Y, Shiroki $\mathrm{H}$, Kinoshita M 1996. Molecular variant of 5, 10methylenetetrahydrofolate reductase is a risk factor of ischemic heart disease in the Japanese population. Atherosclerosis, 121(2): 293-294.

Kalita J, Srivastava R, Bansal V, Agarwal S, Misra UK 2006. Methylenetetrahydrofolate reductase gene polymorphism in Indian stroke patients. Neurology India, 54(3): 260-264.

Kang SS, Wong PW, Malinow MR 1992. Hyperhomocysteinemia as a risk factor for Occlusive vascular disease. Ann.Rev Nutr, 12: 279 -298

Kim CH, Hwang KY, Choi TM, Shin WY, Hong SY 2001. The methylenetetrahydrofolate reductase gene polymorphism in Koreans with coronary artery disease. Int J Cardiol, 78(1): 13-17

Kluijtmans LA, Boers GH, Frost P et al. 1996. Molecular genetic analysis in mild hyperhomocysteinemia: a common mutation in the methylenetetrahydrofolate reductase gene is a genetic risk factor for cardiovascular disease. Am J Hum Genet, 58(1): $35-41$.

Kluijtmans LA, Kastelein JJ, Lindemans J et al. 1997, Thermolabile methylenetetra hydrofolate reductase in coronary artery disease. Circulation, 96(8): 25732577.

Kumar J et al. 2005. Homocysteine levels are associated with MTHFR A1298C polymorphism in Indian population. J. Human Genetics, 50: 655-663

Mc Cully KS 1969. Vascular pathology in hyperhomocystenemia: Implications for the pathogenesis of Arteriosclerosis. Am J Pathology, 56: 111-128.

Meisel C, Cascorbi I, Gerloff T et al. 2001. Identification of six methylenetetrahydrofolate reductase (MTHFR) genotypes resulting from common polymorphisms: impact on plasma homocysteine levels and development of coronary artery disease. Atherosclerosis, 154(3): 651-658.

Misra A et al. 2002. Hyperhomocysteinemia and low intakes of folic acid and vitamin B12 in urban North India. E $J$ Nutrition, 41: 68-77

Morita H, Taguchi J, Kurihara H, et al.1997. Genetic polymorphism of 5,10-methylene-tetrahydrofolate reductase (MTHFR) as a risk factor for coronary artery disease. Circulation, 95(8): 2032-2036.
Naushad SM, Md Nurul Jain Jamal, R. Angalena, C. Krishna Prasad, A. Radha Rama Devi 2007. Hyperhomocysteinemia and the compound heterozygous state for methylene tetra- hydrofolate reductase are independent risk factors for deep vein thrombosis among

South Indians. Blood Coagulation and Fibrinolysis, 18: $113-117$

Nygard O, Nondrehaug JE, Refsum H, Ueland PM, Farstad M, Vollset SE. 1997. Plasma homocysteine levels and mortality in patients with Coronary artery disease. $N$ Engl J Med, 337: 230-236.

Ou T, Yamakawa-Kobayashi, Arinami T. et al. 1998, Methylenetetrahydrofolate reductase and apolipoprotein E polymorphisms are independent risk factors for coronary heart disease in Japanese: a case-control study. Atherosclerosis, 137(1): $23-$ 28.

Pandey SN, Vaidya AD, Vaidya RA, Talwalkar S 2006. Hyperhomocysteinemia as a cardiovascular risk factor in Indian women. Determinants and directionality. J Assoc Physician India, 54: 769774.

Patel JV et al. 2006. Impact of migration on coronary heart disease risk factor: comparison of Gujaratis in Britain and their contemporaries in Indian villages. Atherosclerosis, 186: 297-306

Perry IJ, Refsum H, Morris RW, Ebrahim SB, Ueland PM, Shaper AG 1995. Prospective study of serum total homocysteine concentration and risk of stroke in middle-aged British men. Lancet, 346: 13951398.

Refsum H, Chittaranjan SY, Milind G et al. 2001. Hyperhomocysteinemia and elevated methylmalonic acid indicate a high prevalence of cobalamin deficiency in Asian Indians. A J Clinical Nutrition, 74: 233-241.

Refsum H 2006. "Hordaland homocysteine study: a community based study of homocysteine, its determinants, and association with disease". Journal of Nutrition, 136 (6) suppl: 1731S-1740S

Reinhardt D, Sigusch HH, Vogt SF, Farker K, Muller S, Hoffmann A 1998. Absence of association between a common mutation in the methylenetetrahydrofolate reductase gene and the risk of coronary artery disease. Eur J Clin Invest, 28(1): 20-23.

Sazci A, Emel Ergul, Tuncer N, Akpinar G, Kara I 2006. Methylenetetrahydrofolate reductase gene Polymorphism are associated with ischemic and hemorrhagic stroke: Dual effect or MTHFR polymorphism C677T and A1298C. Brain Research Bulletin, 71: 45-50.

Stampfer MJ, Malinow MR, Willett WC et al. 1992. A Prospective study of homocysteine and risk of homocysteine myocardial infraction in US physicians. JAMA, 268: 877-881.

Stehouwercoen DA, Matty PW, Berg MV, Jakobs C, Feskens EJM, Kromhout D 1998. Serum homocysteine and risk of coronary heart disease and cerebrovascular disease in elderly men a 10 year follow up. Arterioscler Thromb Vasc Biol, 18: 18951901

Tanis BC, Blom HJ, Bloemenkamp DGM, et al 2004. Folat, Homocysteine levels methylenetetrahydrofolate reductase (MTHFR) 677C-T variant, and 
the risk of myocardial infraction in young women: Effect of female hormones on homocysteine level. Journal of Thrombosis and Haemostastisis, 2: 35-41.

Sirachainan N, Tapanapruksakul P, Visudtibham A, Chuansumrit A et al 2006. Homocysteine, MTHFR C677T, Vit B12, and Folate levels in Thai Children with ischemic stroke: A Case-Control study, J Pediatr Hematol Oncol, 28: 803-808.

Taylor LM Jr, De Frang RD, Harris EJ Jr, Porter JM 1991. The association of elevated plasma homocysteine with progression of symptomatic peripheral arterial disease. J Vasc Surg, 13: 128-130

Verhoef P, Hennekens CH, Malinow MR, Kok FJ, Willett WC, Stampfer MJ 1994. A prospective study of plasma homocysteine and risk of ischemic stroke. Stroke, 25: 1924-1930.

Vollset SE, Refsum H, Irgens LM et al. 2000. Plasma total homocysteine, pregnancy Complications and adverse pregnancy out come: The hordaland homocysteine study. Am J clinical Nutr, 71: 962968.

Wolfgang Herrmann 2001. The importance of Hyperhomocystenemia as a Risk factor for diseases: An Overview. Clin Chem Lab Med, 39(8): 666674.

Yoo JH, Park JE, Hong K, Lee S, Kim DK, Lee WR, Park SC 1999. Moderate hyperhomocysteinemia is associated with the presence of Coronary artery disease and the severity of Coronary Atherosclerosis in Koreans. Thrombosis Research, 94: 45-52

Zee Robert YL, Mora S, Cheng S, Erlich H, Lindpaintner, Rifai N, Buring J, Ridker P 2007. Homocysteine, 5, 10, Methylenetetrahydrofolate Reductase 677 C-T polymorphism, Nutrient intake, and incident cardiovascular disease in 24,968 initially healthy women. Clinical Chemistry, 53(5): 1-7 